\title{
Peningkatan Kapasitas Petani Cokelat Desa Randualas Kecamatan Kare Kabupaten Madiun Melalui Edukasi Kualitas Kemasan Produk Cokelat
}

\author{
Achmad Ridwan Ariyantoro*, Choiroel Anam, Raden Baskara Katri Anandito, Danar \\ Praseptiangga, Anastriyani Yulviatun \\ Program Studi Ilmu Teknologi Pangan, Fakultas Pertanian Universitas Sebelas Maret \\ *Correspoding Author : achmadridwan@staff.uns.ac.id \\ Dikirim: 25-11-2020; Diterima: 27-12-2021
}

\begin{abstract}
ABSTRAK
Kakao merupakan salah satu komoditi terbesar di Kabupaten Madiun. Kakao memiliki potensi untuk dikembangkan menjadi produk olahan cokelat yang akan menjadi oleh-oleh khas Kabupaten Madiun. Petani kakao Desa Randualas, Kecamatan Kare, Kabupaten Madiun telah mendapatkan penyuluhan tentang pengolahan biji kakao menjadi produk cokelat yang siap dikonsumsi. Namun, hasil cokelat yang diproduksi masih dikemas hanya menggunakan kemasan primer berupa plastik HDPE dan kurang menarik bagi konsumen, sehingga perlu dilakukan perbaikan kualitas kemasan cokelat yang diproduksi. Tujuan pengabdian masyarakat ini adalah peningkatan kemampuan petani kakao untuk mengemas produk cokelat dengan baik dan menarik sehingga berpotensi meningkatkan daya jual cokelat yang dihasilkan. Kegiatan yang dilakukan meliputi penyuluhan dan sosialisasi cara pengemasan cokelat dan bagaimana mendesain kemasan yang baik dan menarik. Monitoring dan evaluasi dilakukan melalui pengisian kuesioner tingkat pemahaman peserta tentang materi sebelum dan sesudah dilakukan penyuluhan. Hasil menunjukkan bahwa kelompok sasaran mitra memahami pentingnya kemasan dalam produk pangan pada umumnya dan kemasan produk cokelat pada khususnya. Hal ini dibuktikan dengan setelah dilakukan penyuluhan, sebanyak $50 \%$ peserta paham mengenai pentingnya pemilihan jenis dan desain kemasan pangan dan sebanyak $50 \%$ peserta paham mengenai kriteria kemasan yang baik untuk produk cokelat.
\end{abstract}

Kata kunci: kakao, kemasan pangan, pengabdian, pelatihan

\section{Increasing the Capacity of Chocolate Farmers in Randualas Village Kare District Madiun Regency through Education of Chocolate Product Packaging Quality}

\begin{abstract}
Cocoa is one of the largest commodities from Madiun Regency. Cocoa has the potential to be developed into processed chocolate products that will become typical souvenirs of Madiun Regency. The cocoa farmers in Randualas Village, Kare District, Madiun Regency have received counseling on the processing of cocoa beans into ready-to-consume chocolate products. However, the chocolate product was wraped in only an HDPE plastic layer which was less attractive to consumers, so it is necessary to improve the quality of the chocolate packaging. This community empowerment aims to increase the ability of cocoa farmers (partners) to package chocolate products properly and attractively so it will further increase the economic value of their chocolate product. The activities are education and counseling about the importance of packaging for chocolate products and how to design good and attractive packaging. Monitoring and evaluation were also carried out by filling out questionnaires by participants regarding the level of understanding of the material before and after being presented. The result showed that the partners understand the importance of packaging in food products in general and packaging for chocolate products in particular. It was evidenced that after counseling, up to 50\% of participants understand the importance of packaging in the food packaging process and 50\% of participants understand the criteria for good packaging for chocolate products.
\end{abstract}

Keywords: cocoa, community empowerment, food packaging, training 


\section{PENDAHULUAN}

Indonesia merupakan salah satu negara penghasil cokelat terbesar di dunia, bahkan Indonesia menduduki peringkat ketiga dunia eksportir coklat (Anonim, 2019). Hal ini membuat kakao menjadi salah satu penghasil devisa bagi negara. Pada tahun 2018, ekspor biji kakao dan produk olahan kakao mendatangkan devisa hingga USD 1,13 miliar (Marjudin, 2019). Berkaitan dengan produktivitas cokelat di Indonesia, terdapat produksi kakao sebanyak 767.680 ton/tahun pada tahun 2018 (Kementerian Pertanian RI, 2018). Sedangkan, di Kabupaten Madiun tercatat produktivitas kakao dari tahun 2015, 2016 dan 2017 yaitu sebesar $2.791 ; 2.895$ dan 3.145 ton secara berturutan. Dengan jumlah tersebut menempatkan Kabupaten Madiun sebagai tiga besar daerah penghasil cokelat terbesar di Jawa Timur (BPS, 2018a). Produktivitas kakao di Indonesia sebetulnya masih relatif rendah dibandingkan potensi yang dimilikinya. Menurut data Statistik Kakao Indonesia 2017, produktivitas kakao di Indonesia baru sekitar $801 \mathrm{~kg} / \mathrm{ha}$ dari potensinya yang sebesar 1.800 $3.670 \mathrm{~kg} / \mathrm{ha}$ (BPS, 2018b). Pengembangan industri kakao dari hulu ke hilir di Indonesia masih menghadapi banyak kendala, diantaranya disebabkan oleh perkebunan kakao di Indonesia yang didominasi oleh perkebunan rakyat dengan keterbatasan kepemilikan lahan, modal dan keterampilan budidaya (Ariningsih et al., 2019).

Petani kakao di Desa Randualas, Kecamatan Kare, Kabupaten Madiun telah mendapatkan penyuluhan sebelumnya tentang membuat produk olahan produk cokelat yang berupa cokelat couverture. Dimana coklat couverture yang telah dihasilkan telah diperkaya dengan daun kelor (Moringa oleifira) sehingga bisa menjadi pangan fungsional. Menurut Badan $\mathrm{POM}$, pengertian dari pangan fungsional adalah pangan yang secara alamiah maupun telah melalui proses, mengandung satu atau lebih senyawa yang berdasarkan kajian-kajian ilmiah dianggap mempunyai fungsi-fungsi fisiologis tertentu yang bermanfaat bagi kesehatan (BPOM RI, 2011). Akan tetapi kualitas cokelat yang dihasilkan oleh petani di Desa Randualas masih sangat rendah. Selain itu, produk cokelat yang dihasilkan tersebut belum bisa bersaing dengan produk cokelat yang sudah beredar di pasaran sehingga peningkatan kualitas produk cokelat sangat penting dilakukan agar pendapatan masyarakat dapat meningkat.
Peningkatan kualitas produk cokelat salah satunya dapat ditempuh dengan peningkatan desain kemasan yang baik dan menarik. Bentuk, bahan, warna, dan ukuran kemasan dapat mempengaruhi keputusan konsumen dalam membeli produk makanan (Erijanto \& Fibrianto, 2018). Kemasan cokelat yang menarik akan meningkatkan potensi pembeli untuk melirik produk tersebut dan harapannya pembeli bisa membeli produk yang kita jual. Secara teoritis, kemasan produk memiliki lebih dari 100 elemen yang membentuk karakteristik kemasan dan dapat menstimulasi konsumen (Orth \& Malkewitz, 2008). Selama ini, kemasan olahan cokelat dari petani Desa Randualas hanya dikemas secara sederhana dengan plastik HDPE, sehingga tidak menarik bagi konsumen dan berpotensi untuk mudah rusak lebih cepat. Selain itu beberapa jenis kemasan plastik kurang sesuai digunakan sebagai kemasan primer untuk produk berlemak seperti cokelat karena berpeluang terjadi interaksi kimiawi antara monomer plastik dengan komponen lemak (Nugraheni, 2018). Dari uraian tersebut, pengabdian ini sangat penting dilakukan untuk memberikan ilmu pengetahuan dan keterampilan dalam mengemas produk cokelat yang baik dan menarik kepada masyarakat Desa Randualas sehingga dapat meningkatkan jumlah penjualan produk cokelat.

\section{METODE}

Mitra dalam pengabdian ini merupakan Kelompok Wanita Tani Desa Randualas, Kecamatan Kare, Kabupaten Madiun yang berjumlah 20 orang. Kegiatan bercocok tanam kakao merupakan mata pencaharian utama kelompok wanita tani tersebut. Mitra juga merupakan anggota Koperasi Petani Rukun Sejahtera. Petani kakao di Desa Randualas sudah mendapatkan materi tentang praktik mengolah biji cokelat menjadi produk olahan cokelat. Namun keterampilan mereka dalam mengemas produk cokelat masih sangat terbatas, sehingga produk tersebut sulit bersaing dengan produk sejenis di pasaran. Dalam kegiatan pengabdian ini dilakukan beberapa kegiatan yaitu koordinasi awal, sosialisasi dan penyuluhan tentang pentingnya kemasan dalam mengemas makanan dan tentang kemasan yang baik dan menarik, serta evaluasi kegiatan. Kegiatan sosialisasi dan penyuluhan tentang pentingnya kemasan pangan yang baik dan menarik serta bagaimana cara mendesain kemasan produk cokelat yang tepat 
dilakukan secara daring pada 16 September 2020.

Evaluasi pelaksanaan program dilakukan dengan membagikan kuesioner yang berisi beberapa pertanyaan terkait pemahaman peserta tentang materi edukasi. Pertanyaan dalam kuesioner meliputi tingkat pemahaman pentingnya memilih atau mendesain kemasan untuk produk makanan; pemahaman tentang fungsi kemasan untuk produk makanan; pemahaman tentang jenis-jenis kemasan untuk produk makanan; pemahaman tentang ragam informasi yang harus ada di label kemasan untuk produk makanan; pemahaman tentang kriteria kemasan yang baik untuk produk olahan cokelat; dan pemahaman tentang cara mendesain kemasan yang baik dan menarik untuk produk olahan cokelat. Hasil kuesioner lalu dianalisa dengan excel untuk menarik kesimpulan terkait kegiatan monitoring dan evaluasi ini. Pengisian kuisioner evaluasi kegiatan pelatihan pengemasan produk cokelat diselenggarakan secara luring pada periode 17-18 September 2020.

\section{HASIL DAN PEMBAHASAN}

Permasalahan utama dari mitra adalah rendahnya kualitas kemasan produk cokelat. Mitra hanya mengemas produk cokelat dengan sangat sederhana dan hanya menggunakan plastik transparan yang tipis sehingga tidak menarik bagi konsumen. Untuk mengatasi permasalahan mitra tersebut, tim pengabdi melakukan kegiatan untuk memberikan solusi kepada mitra.

\section{Koordinasi awal}

Tim pengabdi telah melakukan koordinasi awal dengan tim pengabdi di Madiun yang akan melakukan kegiatan pengabdian di tempat mitra. Rapat koordinasi ini dihadiri oleh sebagian besar anggota tim pengabdi yang juga merupakan anggota Riset Grup Food Quality and Health, Program Studi Ilmu Teknologi Pangan, Fakultas Pertanian, UNS Surakarta. Rapat koordinasi awal berlangsung di ruang Prodi Ilmu Teknologi Pangan Fakultas Pertanian UNS, pada bulan Juli 2020, pukul 13.00 WIB. Dalam rapat disepakati bahwa kegiatan pengabdian akan dilakukan secara daring dengan pertimbangan utama masih meningkatnya kasus Covid-19 di Soloraya dan Madiun.

Tim pengabdian UNS juga sudah berkoordinasi dengan mitra pengabdian ini dengan bantuan tim dosen D3 THP UNS di Madiun. Dari hasil koordinasi disepakati bahwa sosialisasi tentang proses pengemasan yang baik dan proses mengemas cokelat yang baik dan benar dilakukan secara daring, dimana kelompok wanita tani cokelat Desa Randualas, Kecamatan Kare, Madiun akan diundang ke kampus UNS di Madiun ketika hari pelaksanaan program pengabdian ini. Cara ini ditempuh karena kondisi desa terkendala sinyal internet sehingga tidak memungkinkan untuk dilakukan secara virtual di Desa Randualas.
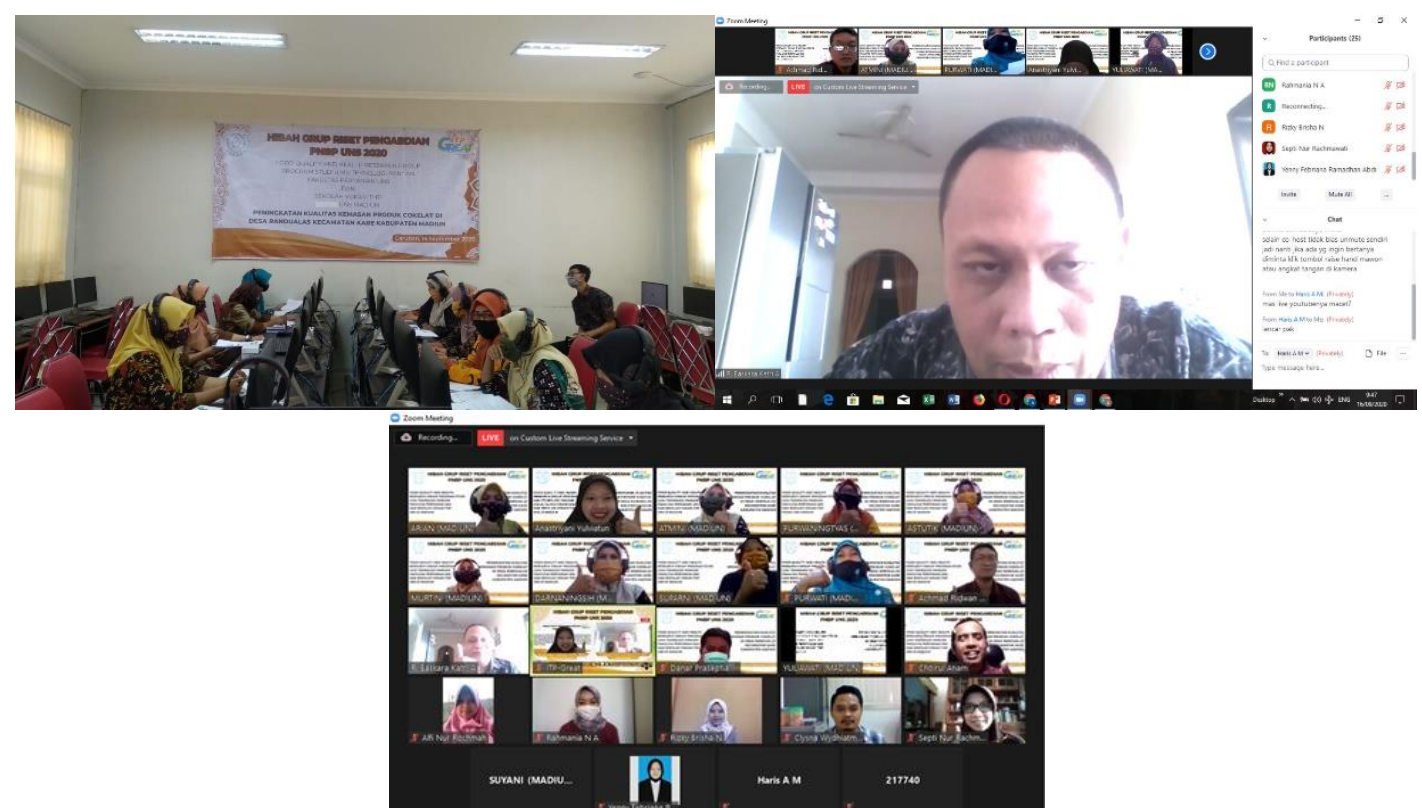

Gambar 1. Kegiatan sosialisasi dan penyuluhan kepada Kelompok Wanita Tani Desa Randualas secara daring melalui zoom 
Tim pengabdian UNS bekerjasama dengan tim dosen D3 THP UNS di Madiun untuk memfasilitasi kelompok wanita tani dalam sosialisasi dan penyuluhan secara daring.

\section{Sosialisasi dan Penyuluhan}

Sosialisasi dan penyuluhan kepada mitra dilaksanakan pada tanggal 13 September 2020. Peserta sebanyak 20 orang hadir dalam kegiatan sosialisasi tersebut yang bertempat di Laboratorium Komputer D3 Teknologi Hasil Pertanian, UNS di Madiun. Kegiatan sosialisasi dan penyuluhan dilakukan secara daring melalui platform zoom dan YouTube sehingga bisa diakses dengan mudah oleh publik. Hal ini dilakukan karena masih tingginya kasus Covid19 di Kota Surakarta dan Madiun. Kegiatan ini diisi dengan materi utama yaitu penyuluhan tentang pentingnya kemasan dalam produk pangan dan juga bagaimana mengemas produk cokelat agar menarik bagi konsumen.

Materi tentang kemasan cokelat ini disampaikan oleh pakar pengemasan pangan yang juga dosen Program Studi Ilmu Teknologi Pangan Fakultas Pertanian UNS, yaitu Raden
Baskara Katri Anandito, S.TP., M.Sc (Gambar 1). Peserta mendapat materi berupa pentingnya kemasan dalam produk pangan, syarat-syarat kemasan yang baik dan bagaimana mengemas produk agar menarik bagi konsumen.

Dalam penyuluhan ini juga disampaikan berbagai macam jenis kemasan dan produk yang dikemas dan kaitan pemilihan kemasan yang tepat untuk produk makanan agar produk tersebut aman untuk dikonsumsi dan memiliki umur simpan yang panjang. Jenis kemasan yang dipaparkan meliputi empat bahan yang umum digunakan sebagai kemasan, yaitu kertas dan sejenisnya, plastik, gelas, dan logam (BPOM RI, 2007). Selain itu disampaikan juga tentang fungsi kemasan, dimana fungsi utama dari kemasan adalah melindungi produk dari kerusakan (Pulungan et al., 2018) dan sebagai identitas produk yang juga menampilkan estetika produk (Julianti, 2015). Dalam materi ini disampaikan kriteria apa saja yang merupakan kemasan yang baik untuk mengemas produk makanan, khususnya cokelat. Disamping itu juga, dilakukan penyuluhan dan sosialisasi tentang bagaimana mendesain sebuah kemasan agar terlihat menarik bagi konsumen.

Tabel 1. Tingkat pemahaman Kelompok Wanita Tani Desa Randualas sebelum dan sesudah penyuluhan

\begin{tabular}{|c|c|c|c|}
\hline \multirow[t]{2}{*}{ No. } & \multirow[t]{2}{*}{ Pertanyaan } & \multicolumn{2}{|c|}{ Tingkat pemahaman } \\
\hline & & Pra & Pasca \\
\hline 1 & $\begin{array}{l}\text { Pemahaman tentang pentingnya memilih } \\
\text { atau mendesain kemasan untuk produk } \\
\text { makanan }\end{array}$ & $\begin{array}{l}\text { Belum } \\
\text { memahami } \\
(100 \%)\end{array}$ & $\begin{array}{c}\text { Paham }(50 \%) \\
\text { Agak paham }(40 \%) \\
\text { Kurang paham }(10 \%)\end{array}$ \\
\hline 2 & $\begin{array}{l}\text { Pemahaman tentang fungsi kemasan untuk } \\
\text { produk makanan }\end{array}$ & $\begin{array}{l}\text { Belum } \\
\text { memahami } \\
(100 \%)\end{array}$ & $\begin{array}{c}\text { Sangat paham }(10 \%) \\
\text { Paham }(30 \%) \\
\text { Agak paham }(60 \%)\end{array}$ \\
\hline 3 & $\begin{array}{l}\text { Pemahaman tentang jenis-jenis kemasan } \\
\text { untuk produk makanan }\end{array}$ & $\begin{array}{l}\text { Belum } \\
\text { memahami } \\
(100 \%)\end{array}$ & $\begin{array}{c}\text { Paham }(60 \%) \\
\text { Agak paham }(40 \%)\end{array}$ \\
\hline 4 & $\begin{array}{l}\text { Pemahaman tentang ragam informasi yang } \\
\text { harus ada di label kemasan untuk produk } \\
\text { makanan }\end{array}$ & $\begin{array}{l}\text { Belum } \\
\text { memahami } \\
(100 \%)\end{array}$ & $\begin{array}{c}\text { Sangat paham }(10 \%) \\
\text { Paham }(30 \%) \\
\text { Agak paham }(50 \%) \\
\text { Kurang paham }(10 \%)\end{array}$ \\
\hline 5 & $\begin{array}{l}\text { Pemahaman tentang kriteria kemasan yang } \\
\text { baik untuk produk olahan cokelat }\end{array}$ & $\begin{array}{l}\text { Belum } \\
\text { memahami } \\
(100 \%)\end{array}$ & $\begin{array}{c}\text { Sangat paham }(10 \%) \\
\text { Paham }(50 \%) \\
\text { Agak paham }(30 \%) \\
\text { Kurang paham }(10 \%)\end{array}$ \\
\hline 6 & $\begin{array}{l}\text { Pemahaman tentang cara mendesain } \\
\text { kemasan yang baik dan menarik untuk } \\
\text { produk olahan cokelat }\end{array}$ & $\begin{array}{l}\text { Belum mengerti } \\
\qquad(10 \%)\end{array}$ & $\begin{array}{l}\text { Sangat paham }(10 \%) \\
\text { Paham }(40 \%) \\
\text { Agak paham }(50 \%)\end{array}$ \\
\hline
\end{tabular}


Kemasan dapat meningkatkan citra produk dan mempengaruhi persepsi konsumen terhadap produk tersebut (Kuvykaite et al., 2009). Desain kemasan cokelat yang menarik dapat dibuat dengan memperhatikan 3 elemen penting, yaitu bentuk kemasan, ukuran kemasan dan material kemasan (Richo, 2017). Dengan kemasan yang menarik tersebut diharapkan dapat menaikkan omzet penjualan dan dapat meningkatkan pendapatan serta taraf ekonomi masyarakat khususnya bagi kelompok wanita tani cokelat Desa Randualas, Madiun.

\section{Evaluasi Kegiatan}

Tim pengabdian mengevaluasi sejauh mana kelompok tani Desa Randualas memahami semua materi yang diberikan oleh narasumber sehingga diharapkan dapat mempraktikkannya dalam mengemas produk cokelat tersebut. Kegiatan pengabdian masyarakat ini berkontribusi memberikan pemahaman terhadap mitra mengenai urgensi kemasan produk cokelat (Tabel 1). Hal ini terlihat dari hasil evaluasi dimana sebagian besar peserta baru mengetahui mengenai fungsi-fungsi kemasan dalam produk pangan, kriteria yang baik dalam mengemas produk cokelat, dan bagaimana mengemas produk cokelat dengan baik dan menarik. Berdasarkan angka persentase pada kolom tingkat pemahaman mitra pasca kegiatan, lebih dari $50 \%$ peserta memahami materi tersebut. Sedangkan sebelum sosialisasi dan penyuluhan, semua $(100 \%)$ peserta belum mengerti materi yang disampaikan.

\section{KESIMPULAN}

Sosialisasi dan penyuluhan tentang pengemasan produk cokelat kepada mitra sasaran berhasil meningkatkan pemahaman pada mitra tentang pentingnya kemasan dalam produk pangan, dimana berdasarkan hasil evaluasi 50\% dari total peserta pelatihan memahami pentingnya kemasan produk cokelat dan bagaimana mendesain kemasan yang baik untuk produk olahan cokelat. Setelah pelatihan, lebih dari $50 \%$ peserta memahami fungsi kemasan produk pangan, jenis-jenis kemasan produk pangan, dan kriteria kemasan yang baik untuk cokelat. Hal ini diharapkan meningkatkan kapasitas kelompok wanita tani kakao Randualas untuk menghasilkan produk olahan cokelat dengan daya jual lebih tinggi melalui perbaikan kemasannya.

\section{UCAPAN TERIMA KASIH}

Penulis menyampaikan ucapan terima kasih kepada Universitas Sebelas Maret yang telah mendanai kegiatan pengabdian ini melalui skema Program Kemitraan Masyarakat Hibah Riset Grup pendanaan PNBP UNS Tahun Anggaran 2020, melalui Perjanjian Pelaksanaan Pengabdian Kepada Masyarakat Nomor : 453/UN27.21/PN/2020.

\section{DAFTAR PUSTAKA}

Anonim. (2019). Indonesia tak lagi ekspor coklat mentah. https://indonesia.go.id/narasi/indonesiadalam-angka/ekonomi/indonesia-taklagi-ekspor-coklat-mentah

Ariningsih, E., Purba, H. J., Sinuraya, J. F., Suharyono, S., \& Septanti, K. S. (2019). Kinerja industri kakao di Indonesia. Forum Penelitian Agro Ekonomi, 37, 123.

https://doi.org/10.21082/fae.v37n1.2019. $1-23$

BPOM RI. (2007). Bijak dalam Menggunakan Kemasan Pangan. https://pom.go.id/new/view/more/berita/1 74/Bijak-dalam-Menggunakan-KemasanPangan.html

BPOM RI. (2011). Peraturan kepala badan pengawas obat dan makanan Republik Indonesia

nomor

HK.03.1.23.11.11.09909 tahun 2011 tentang pengawasan klaim dalam label dan iklan pangan olahan.

BPS. (2018a). Produksi perkebunan kakao menurut Kabupaten/Kota di Jawa Timur Tahun 2006-2017. In BPS Provinsi Jawa Timur.

https://jatim.bps.go.id/statictable/2018/11 /12/1392/produksi-perkebunan-kakaomenurut-kabupaten-kota-di-jawa-timurton-2006-2017.html

BPS. (2018b). Statistik kakao Indonesia 2017 (Sub Direktorat Statistik Tanaman Perkebunan (ed.)). Badan Pusat Statistik.

Erijanto, A. C., \& Fibrianto, K. (2018). Variasi kemasan terhadap tingkat kesukaan dan pengambilan keputusan konsumen pada pembelian makanan tradisional: Kajian pustaka. Jurnal Pangan dan Agroindustri, 6(1), 91-96. https://doi.org/10.21776/ub.jpa.2018.006. 01.11 
Julianti, S. (2015). The Art of Packaging. PT Gramedia Pustaka Utama.

Kementerian Pertanian RI. (2018). Produksi Kakao Menurut Provinsi di Indonesia 2016 - 2020.

Kuvykaite, R., Dovaliene, A., \& Navickiene, L. (2009). Impact of package elements on consumer's purchase decision. Economics and Management, 14, 441-447.

Marjudin. (2019). Industri kakao sumbang devisa negara hingga USD1,13 miliar. https://www.indopremier.com/ipotnews/n ewsDetail.php?jdl=Industri_Kakao_Sum bang_Devisa_Negara_Hingga_USD1_13 _Miliar\&news_id=110041\&group_news $=$ IPOTNEWS\&news_date $=\&$ taging_subt ype $=$ PERKEBUNAN\&name $=\& \operatorname{search}=y$ _general\&q=kakao, cokelat\&halaman $=1$
Nugraheni, M. (2018). Kemasan Pangan. Plantaxia.

Orth, U. R., \& Malkewitz, K. (2008). Holistic package design and consumer brand impressions. Journal of Marketing, 72(3), 64-81. https://doi.org/10.1509/JMKG.72.3.064

Pulungan, M. H., Dewi, I. A., Rahmah, N. L., Perdani, C. G., Wardina, K., \& Pujiana, D. (2018). Teknologi pengemasan dan penyimpanan. UB Press.

Richo, Y. (2017). Desain produk kemasan cokelat dengan menggunakan peran elemen fungsional desain. Jurnal Desain Idea, 16(2), 1-5. https://doi.org/10.12962/iptek_desain.v16 i2.3586 